\title{
Complexity Theory: Insights from a Canadian ERP Project Implementation
}

\author{
Sreekumar A. Menon ${ }^{1}$, Marc Muchnick ${ }^{2}$, Clifford Butler ${ }^{3} \&$ Tony Pizur ${ }^{4}$ \\ ${ }^{1}$ Management consultant \& Director R3Synergy Inc., Calgary, Canada \\ ${ }^{2}$ Professor, School of Business \& Technology, Capella University, Minneapolis, USA \\ ${ }^{3}$ Chair, SOBT Doctoral Programs, Capella University, Minneapolis, USA \\ ${ }^{4}$ Professor, School of Business \& Technology, Capella University, Minneapolis, USA \\ Correspondence: Dr. Sreekumar Menon, Management Consultant \& Director, R3Synergy Inc., Calgary, Canada. \\ E-mail: ask_menon@yahoo.com
}

Received: April 72019

doi:10.5539/ijbm.v14n6p84
Accepted: May 5, 2019

Online Published: May 16, 2019

URL: https://doi.org/10.5539/ijbm.v14n6p84

\begin{abstract}
This research paper explores complexity theory based on insights from an Enterprise Resource Planning (ERP) implementation in the Canadian oil and gas industry. The qualitative exploratory case study was conducted in a Canadian case organization using a semi-structured interview guide with a total of twenty interviews from members of four project role groups of senior leaders, project managers, project team members, and business users. Besides interview responses, the study also collected and reviewed ERP project documents for triangulation purposes. The research showed the importance of complexity theory to ERP projects, and the relationship between critical challenges and complex categories of human behavior, system behavior, and ambiguity. The study findings also evoked rich and comprehensive data related to the phenomenon of critical challenges in ERP.
\end{abstract}

Keywords: Enterprise Resource Planning (ERP), implementation, exploratory single-case study, triangulation, complexity theory

\section{Introduction}

Although ERP applications are widely used by organizations worldwide, there is a growing concern about the critical challenges faced during Enterprise Resource Planning (ERP) implementation (Momoh, Roy \& Shehab, 2010). Despite high costs and lengthy time frames, ERP projects do not perform according to business expectations (Davenport, 1998; Tarn et al., 2002; Ehie and Madsen, 2005; Momoh et al., 2010; Stanciu \& Tinca, 2013). There is also a lack of understanding on addressing critical challenges during implementation, which can lead to large cost overruns, cancellations, and project failures (Momoh et al., 2010; Stanciu \& Tinca, 2013). This qualitative, exploratory single-case study is an examination of complexity theory in the field of ERP implementation and, in particular, affecting the oil and gas industry (Cooke-Davies \& Crawford, 2011; Tambovcevs \& Merkuryev, 2009).

Complexity theory deals with dynamic, non-linear systems and examines how complex patterns, states, and structures tend to surface from simple underlying rules, even though such patterns, states, and structures arise from complicated systems (Burnes, 2005; Cooke-Davies \& Crawford, 2011). Any ERP project may consist of interconnected elements or parts with related and unpredictable changes and this displays the attributes of complex systems. Whereas specific outcomes are expected once projects are executed and complete, complexity theory characterizes outcomes as unpredictable and chaotic in nature (Pundir, Ganapathy, \& Sambandam, 2007). When projects are too complex, reducing complexity is an important goal of project managers. Understanding critical challenges can prove valuable in predicting a project outcome during an ERP project implementation (Cooke-Davies \& Crawford, 2011).

\subsection{Complexity Theory Background}

Complexity theory originated from meteorologists' studies seeking to manage weather systems using mathematical tools and models (Cooke-Davies \& Crawford, 2011). Continuously changing, dynamic, non-linear 
systems are those in which the laws of cause and effect seldom apply. Complexity theory deals with complex structures and complicated systems, though the behavior can originate from simple rules (Burnes, 2005; Cooke-Davies \& Crawford, 2011). Because of its focus on the changing of non-linear situations, complexity theory can be very useful to management for predicting and improving the performance of organizations (Stacey, 1995). Complexity theory studies how complex structures and behaviors tend to surface from simple underlying rules even though such patterns, states, and structures arise from complicated systems (Cooke-Davies \& Crawford, 2011). Perceiving the applications of the complexity model, physicists, biologists, chemists, and other scientists began applying this approach to their own research areas, such as economics, international relations, and medicine (Burnes, 2005; Levy, 1994). Complexity theory has significant applications in the management of organizations, as most organizations have the properties of non-linear, dynamic, and complex systems.

Complexity theory provides analytical methods and insights, which can be adapted to complex environments once systems are well understood. Complexity theory is characterized by terms such as chaos, non-linear dynamics, fractals, self-organization, fitness landscapes, emergence, dissipative structures, complex adaptive systems, and indeterminacy (Cooke-Davies et al., 2007; Nunn, 2007). Important concepts such as emergence, complex adaptive systems, and indeterminacy are the fundamental tenets of the future of complex dynamical systems. Emergence refers to the characteristics of self-organizing systems that are different in degree from their organizational constituents. Emergence allows innovation despite the presence of unpredictable elements in complex systems. Complex adaptive systems, including some natural systems (such as a brain or a society), have the ability to learn from their own experience, and to assimilate to the changes in environment. The characteristic of another emerging trait, indeterminacy, recognizes the indeterminacy of the future of dynamical systems, emphasizing that even physical matter shows inherent uncertainty (Cooke-Davies \& Crawford, 2011).

Feedback is yet another critical feature of complex systems in which output becomes input, as the system recycles the same process. A complex system is considered robust because of its ability to organize itself related to the environment with a long memory. The feedback mechanisms cause difficulty in illustrating events and casual predictions in complex systems (Rickles, Hawe, \& Shiell, 2007). Complexity theory has widespread application to most disciplines, including the fields of project management, medicine, economics, and business.

\subsection{Foundational Studies on Complexity Theory and ERP}

Simpson and Simpson's 2009 study on systems of systems complexity, identification, and control, explored the connection between classical systems engineering techniques and design structured matrices in order to address the computational complexity and cognitive complexity associated with system of systems life-cycle events. The enhancement of human perception using computational techniques is the key aspect explored by Simpson and Simpson (2009). Simpson and Simpson (2009) defined complexity as a measure of difficulty, effort, or resources - or some combination thereof-required for one system to effectively observe, communicate, interoperate, or use some combination of these three actions with another system (p. 1). The range of complexity types includes cognitive complexity, perceptual complexity, a combination of cognitive and perceptual complexity, behavioral complexity, organic complexity, and computational complexity. The Simpson and Simpson study (2009) revealed that classical system techniques can reduce complexity by focusing on the relationship between associated values of interrelationships and components.

Ghosh and Skibniewski (2010) provided a systematic explanation of complexities by investigating critical success and risk factors in ERP implementations. Citing Remington and Pollack (2008), Ghosh and Skibniewski refered to four types of complexity in the study: structural, technological, directional and temporal. Ghosh and Skibniewski (2010) also evaluated complexity dimensions with respect to the critical success factors from Moon (2007). Some of the complexity examples examined include top management support and commitment (structural and directional); ERP team competence, composition, and compensation (temporal and structural); project management and evaluation (structural); user training and evaluation (structural); and enterprise-wide communication and cooperation (directional and temporal). Ghosh and Skibniewski asserted that ERP projects are likely to exhibit the attributes of structural complexities.

The research by Geraldi, Maylor, and Williams (2011) "now let's make it really complex (complicated): A systematic review of the complexities of projects" is another foundational work which offers an integrated framework for managing project complexities and provides an explanation of the epistemology of complexity. Complexity within complexity theory is about dynamics, emergence, non-linearity, and other behaviors that are present in systems of interrelated elements (Geraldi et al., 2011). The authors present five dimensions of complexity: (a) structural complexity, (b) uncertainty, (c) dynamics, (d) pace, and (e) socio-political complexity. 
Structural complexity relates to many interdependent and distinct elements, which has three attributes of size, variety, and interdependence. Uncertainty can solve new problems and can be involved in creating something unique; in other words, it is the "complexity of faith" (Geraldi et al., 2011). Dynamics refers to specification changes; changes in projects; and changes to goals, suppliers, environment, and management team. Any or all of these changes can lead to rework, inefficiency, or project disorder, particularly when the changes are not communicated well. Dynamic complexity can result from scope changes, and from uncertainty due to the emergence of disruptive or new technologies (Geraldi et al., 2011). Pace, another dimension of complexity, refers to the rate at which projects are delivered; it is a temporal aspect of complexity (Geraldi et al., 2011). Finally, socio-political complexity emerges as a combination of emotional and political aspects in projects, and this dimension of complexity is strong in mergers and acquisitions, organizational change, or wherever opinions, interests, and agendas have high stakes (Geraldi et al., 2011). According to Geraldi et al. (2011), it is vital to develop responses to project complexities that correctly represent the realities of projects, and to develop approaches to fit these realities.

The study by Spiteri, Luca, Reynolds, and Wilson (2012) "defining a baseline complexity model for ERP systems over SaaS" discussed three different kinds of complexity theories for defining a baseline complexity model applicable to ERP systems. These three theories are complex system theory, programmatic complexity, and network complexity. The Salmeron and Lopez (2012) study on forecasting risk impact showed the significance of a dynamic simulation tool for foreseeing the impact of risks on maintenance goals in complex ERP projects. One of the risk elements highlighted by Salmeron and Lopez (2012) was personnel turnover rate, such as a technical consultant's or developer's departure, which can negatively affect cost and increase project delays. Salmeron and Lopez (2012) pointed out that ERP maintenance projects are higher in complexity than other software projects due to the large number of connected applications, changes to system pre- and post-implementations, and actors involved; the large size of ERP systems adds complexity as well.

The empirical study on "supply-chain uncertainty: A review and theoretical foundation for future research" by Simangunsong, Hendry, and Stevenson (2012) identified 14 resources related to uncertainty, and highlighted several approaches to managing uncertainty, such as reducing uncertainty at its source and coping with it. Whereas supply-chain uncertainty is a complex phenomenon that can occur due to transportation delays and quality problems, global supply chain networks are in themselves complex in nature and difficult to comprehend. Inadequate risk management policies have resulted in significant losses for major companies including Cisco, Pfizer, and Boeing (Simangunsong et al., 2012). Therefore, complexity surrounding uncertainty and risk can impact project performance for organizations in the present competitive market. Simangunsong et al. (2012) also argued that in risk management, the concept of risk mitigation is common. Therefore, and while coping with uncertainty, strategy mitigation must be looked at in the same perspective.

Gregory and Piccinini's study (2013) on the "nature of complexity in Information System projects and programs" addresses the theoretical gap between the lack of understanding about complexity and its constituent constructs, such as variety. The study provides a conceptual aggregation of complexity components into four distinct constructs of complexity: uncertainty, ambiguity, variety, and interdependency. The implications of this study reveal an increased relative importance between the components of organizational complexity and technological complexity, which makes IS programs much more strategic than other projects (Gregory \& Piccinini, 2013).

Jacobs, M. A.'s 2013 study on "enterprise resource planning (ERP): A brief history" discusses empirical measures in complexity and presents a generalized complexity index (GCI) that employs a product structure diagram to create a geometric structure from three complexity dimensions: multiplicity, diversity, and interconnectedness. Whereas complexity is a multi-dimensional construct with no agreed-upon definition, the concept of complexity is often related to ambiguity, uncertainty, difficulty, and novelty (Jacobs, M. A., 2013). The Maylor, Turner, and Murray-Webster (2013) study "how hard can it be? Actively managing complexity in technology projects" presents different dimensions of complexity and their impact while seeking opportunities for organizations to manage complexity in projects. Organizations face increasing complexity due to outsourcing, greater technological uncertainty, and market uncertainty; together, these can create chaos (Maylor et al., 2013). According to Maylor et al. (2013), managing complexity is crucial because the complexity in projects appears to be increasing and according to IBM's essential Chief Information Officer (CIO) survey, it will continue to do so over the next 5 years. Complexity in a project decreases when unknown unknowns, (i.e. unexpected or unforeseeable conditions) become known during a project's life cycle. The study examined three dimensions of complexity: (a) structural complexity, (b) sociopolitical complexity, and (c) emergent complexity

The Browning and Ramasesh (2015) study on "reducing unwelcome surprises in project management" addressed the theory of knowable unknowns. Whereas employing risk management methods can mitigate known risks, 
managing unknown unknowns or "unks-unks" can inject unwelcome surprises and derail project plans. As posited by Browning and Ramasesh(2015), it is therefore important for managers to consider all six domains and corresponding relationships in projects. These are: complexity, complicatedness, dynamism, equivocality, mindlessness, and project pathologies (Browning and Ramasesh, 2015). Evaluating these factors in a project can help managers determine why projects encounter unknown unknowns. According to Browning and Ramasesh (2015), projects are complex, and it is important for managers to understand complexity and unknown unknowns at an early stage of the project. Unwelcome surprises in projects can be reduced by uncovering unknown unknowns, and then converting them into known unknowns, i.e. knowing there are some things that they do not know.

The Mittelstädt, Brauner, Blum, and Ziefle (2015) study "on the visual design of ERP systems: the role of information complexity, presentation and human factors", was based on a multi-factorial experiment and examined the effects of information complexity, presentation, and human factors as key aspects of usability on decision quality. Even with the benefits ERP systems provide, the complexity of these systems generates criticism. To make the right decisions, users must be able to understand data clearly, and therefore displayed information in the ERP system could impact the decision quality (Mittelstädt et al., 2015). The Tong and Arvey (2015) study on "managing complexity via the competing values framework" deals specifically with complexity theory and the three managerial behaviors of enabling, sensemaking, and facilitating shared leadership as central to managing complexity. Managers and leaders must focus on the complexity and its application in projects. This means that although managers may not have all the required individual knowledge related to complex situations, they must use shared knowledge from other employees (Tong \& Arvey, 2015). Tong and Arvey (2015) argued that although scholars apply complexity theory to organizations, the technology and globalization issues bring in bigger complexity problems, and managers must be prepared and able to handle complexity issues in earnest.

\subsection{Complexity in ERP Projects}

ERP projects display attributes of complex systems because they are composed of many interconnected parts with unpredictable changes, which makes projects difficult to manage (Pundir, Ganapathy, \& Sambandam, 2007). ERP projects expect a specific outcome, but complexity theory regards outcomes as chaotic and unpredictable, which contradicts the project management viewpoint (Cooke-Davies \& Crawford, 2011). Even capable project managers may find it difficult to manage projects due to its unpredictable nature. Because of the heavy involvement of several stakeholders, one of the most important elements of project complexity is human behavior. To lower project complexity, stakeholders can set the appropriate expectations by using a goals and method matrix or effective use of hard closed systems or soft open systems (Crawford, Hobbs, \& Turner, 2005; Turner \& Cochrane, 1993). Some key areas of project complexity influencing ERP projects are nonlinearity, scope, culture, and learning.

Nonlinearity. Nonlinearity corresponds to interdependency in complexity theory. Complex projects include many interdependencies, and nonlinearity of outcomes becomes visible in complex projects. For example, slight differences that occur during the project blueprinting stage with stakeholders can significantly influence the outcome of the solution. Such chaos-inducing changes can also take place during the realization or execution phase of the project, affecting the project plan to a great degree (Pundir et al., 2007). According to Chapman and Ward (1997), known problems can find answers in standard project management, and known unknowns can find answers in the risk management process. However, unknown unknowns can affect unplanned outcomes, resulting in notable deviations from the original plan. Key examples of unknown unknowns are the removal of critical resources, such as the project manager, changes to the project reporting structure, and change management issues. These unknown and sudden changes can cause greater disturbance and turbulence, significantly affecting the very existence of the project itself.

Scope. Clearly defining scope is critical to ERP projects, and lack of proper scope definition can make a project excessively complex. The scope of the project can change due to recurring, and often frequent, interference from stakeholders. Such scope changes increase rework, delays, and costs as well as changing the scope of the project itself (a phenomenon known as "scope creep"), which can change the course of the project or render it unviable (Besner \& Hobbs, 2012). Therefore, managers must try to capture all internal and external influences in the scope document. Short ERP projects are easier to control than long-duration projects. To overcome complexity in ERP projects, it can be very helpful to use project management techniques to keep projects short and well-defined (Cooke-Davies \& Crawford, 2011).

Culture. Culture is composed of the shared beliefs, norms, values, and traditions that bind the organization together. For organizational success, understanding the cultural complexity is relevant and critical, since values 
and assumptions are shared throughout an organization (Maylor et al., 2013; Tong \& Arvey, 2015). Project managers face challenges while managing persons with diverse backgrounds, as project teams can consist of people belonging to multicultural backgrounds. Where projects have a global nature, managers must handle tensions caused by ethical and cultural differences, as well as language and personality issues. Project managers can instill organizational vision into the culture, which helps to overcome complexity arising from cultural issues and lead ERP projects to success.

Learning. Pich, Loch, and Meyer (2002) argued that a project team must be adequately trained to deliver optimal solutions, and the signals generated from projects will indicate whether there is a need for training. The project manager plays an important part in studying the signals before making a final decision on the type of training required for the project team. As new learning consumes time and effort, proper planning is essential so that the project team gathers all the relevant knowledge to tackle complex project problems (Pich et al., 2002). In fact, it may be a challenge to provide training for team members while the project is in full swing, as the training may affect the deliverables and project timeline.

\section{Complexity Categories: Project Management Institute (PMI) View}

According to PMI (2014), causes of complexity in ERP projects can be grouped into three broad categories (Figure 1). These categories are human behavior, system behavior, and ambiguity. Certain underlying causes reside within each of the categories, and it is imperative that management understand these causes to meet the challenges of complexity in projects (PMI, 2014).

Human behavior. The human factor is a source of complexity that can emerge from the interplay of attitudes, demeanors, and conduct (PMI, 2014). The key causes related to human behavior are: (a) individual behavior, (b) group, organizational, and political behavior, (c) communication and control, and (d) organizational design and development (PMI, 2014). Projects are composed of team members with diverse ethnic, cultural, and educational backgrounds, as well as diverse technical skills.

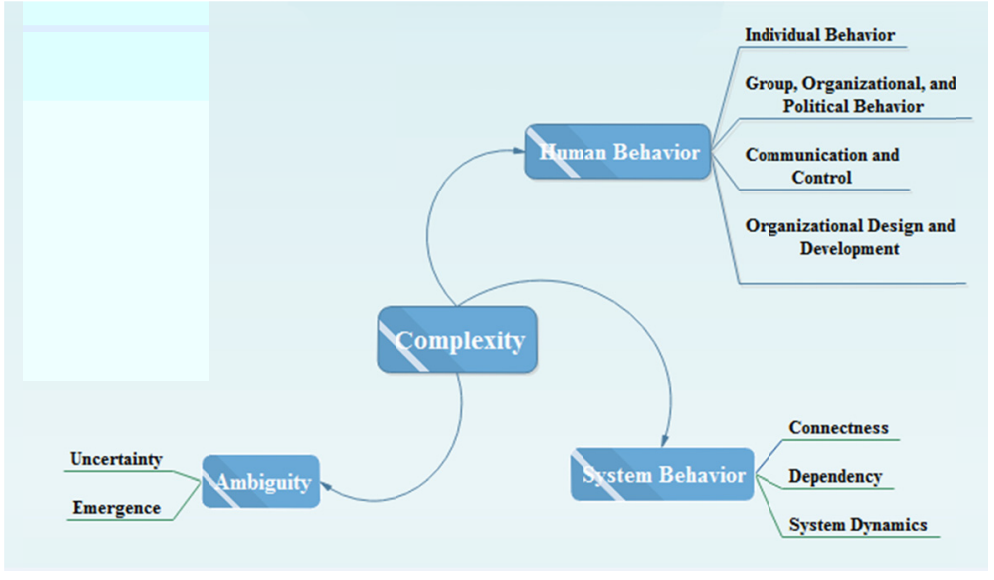

Figure 1. Complexity categories and associated causes

Source: Adapted from Navigating Complexity: A Practice Guide, p.12, by PMI, 2014. Project Management Institute. Copyright 2014, by PMI

When people start working on projects, individual differences can create issues. Changes to scope and schedule, delayed decisions, complicated decisions, lack of trust among team members, poor morale, and leadership issues can result in making the project more complex. Lack of proper communication between internal and external stakeholders, among project teams, and with vendors, steering committee, and other interested parties can create significant issues; these issues can further increase project complexity (Cooke-Davies \& Crawford, 2011). Human behaviors can disrupt identifying project goals. Effective interactions with stakeholders are imperative to reduce the complexity experienced in ERP projects (Momoh, 2015; PMI, 2014).

System behavior. According to PMI (2014), projects and programs are considered as systems within systems. In a complex environment, projects and programs are interdependent through connections among their components or parts (PMI, 2014). Therefore, complexity can surface as a result of component connections and also whenever there is a disconnect between any of these components (PMI, 2014). PMI (2014) defines a system as a collection of different components, which together can produce results not obtainable by the components alone. Also, when 
the number of components increases in projects or programs, complexity increases significantly. If $n$ is the number of connected components, the number of connections can increase by $n^{*}(n-1) / 2$ (PMI, 2014). Therefore, when many unrelated components are connected, the complexity increases significantly. PMI (2014) maintained that as multiple changes occur in a system and between the system and its environment, adaptive behavior occurs within its components, which in turn adds to the system's dynamics. Complexity in system behavior can occur due to (a) connectedness, (b) dependency, and (c) system dynamics.

Ambiguity. Ambiguity, which is a common aspect in projects and programs of complexity, is the state of being unclear, of not knowing what to expect or how to comprehend a situation (Hass, 2009; PMI, 2014). In other words, ambiguity can be described as confusion, lack of understanding, and disagreement (Gregory \& Piccinini, 2013). The two causes of ambiguity that contribute to the complexity of a project, either independently or in combination, are emergence and uncertainty (PMI, 2014).

Emergence. Emergence is an unanticipated gradual or spontaneous change; it is initially invisible but becomes visible within the context of a project or program (PMI, 2014). Emergence arises from dynamic interrelationships to produce new and unforeseen opportunities and situations among and between project components, for example, program or project processes and stakeholders (PMI, 2014). An emergent behavior or characteristic can replace existing behaviors and determine new ones, thereby creating a new dynamic in the project (PMI, 2014). Emergence may have a positive or negative impact on innovation and using adequate change and risk management methodologies; a negative impact can be minimized, and a positive impact can be enabled (PMI, 2014).

Uncertainty. Uncertainty is the state of being unsure; of not knowing a situation or issue; a lack of understanding and awareness of issues, events, a path to follow, or solutions to pursue; and also, in which the elements of a project are subject to future changes (Hass, 2009; PMI, 2014). In effective project management, answers can be found for the known problems and known unknowns of the risk management process (Chapman \& Ward, 1997). However, significant deviations from the plan can result in unplanned outcomes, which in turn create unknown unknowns. Some of the important examples of unknown unknowns are (a) issues resulting from the change management process, (b) changes in the reporting structure, and (c) the impact of critical resource changes or removals. Slight differences among stakeholders that occur during blueprinting, realization, and execution can also greatly affect the project plan (Pundir et al., 2007). All these significant changes and unknowns can impact the project, causing turbulence that affects the survival of an ERP project. Uncertainty is one of the important characteristics of project complexity, and it can cause untimely and ambiguous decisions resulting in no clear direction for the outcome, a lack of common goals, and complications arising from technological issues (Remington \& Pollack, 2007). ERP projects can exceed schedules or budgets because of these unpredictable conditions, even with effective use of project management tools and methodologies.

Chaos, unforeseen uncertainty, foreseen uncertainty, and variation are the four unique project uncertainties identified by Meyer, Loch, and Pich (2002). Chaos can occur when the project's defined goals and purpose cannot be matched with the project results. Unforeseen uncertainty, or unknown unknowns, are events that are impossible to determine during the planning process. Distinct influences or foreseen uncertainty can be effectively mitigated using a risk management plan (Meyer et al., 2002). Variations occur when small influences, such as sudden system challenges or health issues of team members, result in changes to a project schedule and budget. Complexity theory therefore has major applications in ERP project management and within the diverse complexity categories of human behavior, system behavior, and ambiguity (Cooke-Davies \& Crawford, 2011; Hass, 2009; PMI, 2014).

\subsection{Relationship between ERP Projects, Complexity, and Critical Challenges}

The literature review revealed the existence of relationships between ERP projects, complexity, and critical challenges (see Figure 2). According to Momoh (2015), challenges are problems caused by complexity, which can lead to project failure; and the reason for software failure is complexity (Bansal \& Negi, 2008). The literature review discussed PMI's three complexity categories of human behavior, system behavior, and ambiguity (PMI, 2014). These complexity dimensions are mapped against key critical challenges as highlighted in Table 1. These three complexity categories from PMI (2014) will be used as a basis for defining the critical challenges against theoretical implications for the current study. 


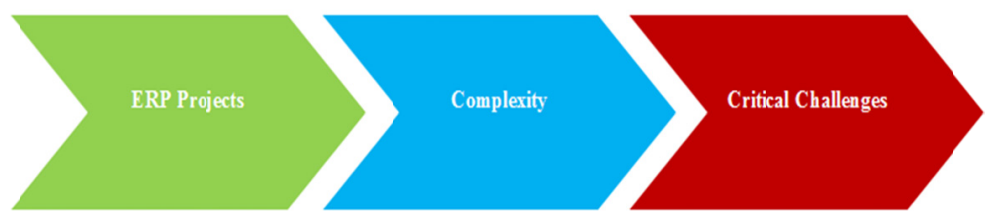

Figure 2. The relationship between ERP projects, complexity, and critical challenges

Table 1. Mapping complex categories and critical challenges

\begin{tabular}{|c|c|c|c|}
\hline \multirow[b]{2}{*}{ Critical Challenges } & \multicolumn{3}{|l|}{ Complex Category } \\
\hline & Human Behavior & System Behavior & Ambiguity \\
\hline Lack of Top Management Support & $\mathrm{X}$ & & \\
\hline Excessive Customization & & $\mathrm{X}$ & \\
\hline Poor Data Quality & & $\mathrm{X}$ & \\
\hline Lack of Change Management & $\mathrm{X}$ & & $\mathrm{X}$ \\
\hline Inadequate Training & $\mathrm{x}$ & & \\
\hline
\end{tabular}

\section{Methodology}

The research study used a qualitative exploratory single-case study design in order to understand the perceptions of each of the four project role groups with respect to critical challenges in ERP implementation. Exploratory case study research is used to investigate a phenomenon by understanding perceptions and is usually focused on a small sample population for arriving at in-depth and rich data (Hewlett, 2005; Yin, 2014). Qualitative exploratory case studies typically involve small heterogeneous samples can offer in-depth investigation, and such a case study is considered an appropriate tool for undertaking research in ERP implementation (Yin, 2009; Mishra \& Mishra, 2011). Important characteristics applicable to exploratory case study research were aligned with this study's objectives. These were enabling deep focus on scope, instead of a broad focus, generating hypotheses rather than testing them, and exploring a heterogeneous population instead of a homogeneous one (Gerring, 2007). The study design was also conducive to identifying rich insights into the identified role groups' perceptions and differences (Woodside, 2010). This exploratory case study research also involved in collecting documentation, archived records, or both (Denzin, 2012; Howe, 2012; Nickson, 2014).

The case setting used for the current study is a Canadian oil and gas company involved in ERP implementation. Three oil companies in Canada were identified as having integrated refining capabilities such as upstream, downstream, and retail business capabilities. All three organizations had significant staff size and ERP implementation project history. For general guidance toward site selection for a qualitative case study exploring ERP in the oil and gas industry, examples were drawn from the literature (Mishra \& Mishra, 2011). The researcher used professional business contacts from personal experience in ERP implementation in the Canadian oil and gas industry to identify three suitable organizations. These organizations typically employed more than 5000 employees in the local market, and each has a good IT presence. One of the three suitable Canadian oil and gas companies agreed to participate in the study. The inclusion criteria required that the participants must have experience in ERP project roles. The participants also must have worked in ERP implementation projects in the Canadian oil and gas industry. The organization assisted in soliciting employee participation; however, participants were selected based on inclusion criteria and on a first-response basis.

\subsection{Data Collection}

Stratified sampling was used due to the small sample size and the desire to obtain data from each stratum or participant group of the sample (Gerring, 2007). Twenty participants were selected for this study using stratified purposive sampling from the chosen Canadian oil and gas company. The sample represents four participant project team roles that consisted of three senior leaders, four project managers, six project team members, and seven business users, for a total of 20 subjects. Characteristics that were noted but not used as selection criteria included project-team member age level, overall employment experience, and educational level. McLeod (2010) suggested that case-study research advocates for participants be knowledgeable about the phenomenon in its context, which was a requirement for participant inclusion in this study. The inclusion criteria required that the participants must have experience in ERP project roles and also must have worked in ERP implementation projects in the Canadian oil and gas industry. The organization assisted in soliciting employee participation; however, participants were selected based on inclusion criteria and on a first-response basis. 
The draft interview guide was composed of interview questions and compiled based on research questions for the current study. The research was field-tested using SMEs and role-players. The final interview guide was divided into six sections: (a) organizational and administration details, (b) organizational circumstances, (c) best practices, (d) barriers or challenges, (e) strategies, and (f) recommendations. To lessen interviewer bias, all questions were asked in the same order (Gubrium \& Holstein, 2001). All the interviews were held in a safe public place and was recorded using two digital audio recorders. In this study document review facilitated data triangulation, which provided another source of data beyond the semi-structured interviews with senior leaders, project managers, project team members, and business users (Yin, 2009; Denzin, 2012; Howe, 2012; Nickson, 2014).

\subsection{Data Analysis}

The researcher conducted a total of 20 face-to-face interviews with participants from the four project team role groups: senior leaders, project managers, project team members, business users. The researcher's step-by-step analysis are detailed in the following numbered list:

1. The researcher recorded the in-person interviews and took notes;

2. The researcher transcribed the audio files, and organized the notes for data entry;

3. The researcher entered the collected data into NVivo software for data coding and analysis;

4. The researcher triangulated multiple data sources to address interview data among four groups as well as between interview data and documents collected (Jonsen \& Jehn, 2009);

5. The researcher prepared charts and graphs with NVivo software and Microsoft Excel to illustrate the data results; and

\section{The Researcher Conducted Data Analysis}

The researcher asked participants belonging to project team role questions from the semi-structured final interview guide. The researcher grouped, and categorized responses based on the identified themes from the research questions. The researcher organized collected data for similarities, as the purpose of the data analysis was to pinpoint repeatable regularities to show themes or patterns of belief (Miles \& Huberman, 1994). Because of ethical considerations, specific subject names, organization details, and anything that could cause potential risk was omitted from the report (Academy of Management, 2015; Trochim \& Donnelly, 2006). Qualitative data analysis software NVivo 11, by QSR International (2016), was used to organize, tabulate, and code the interview responses. The identified themes and findings were loaded into NVivo for qualitative data analysis using the following steps.

1. Read transcripts and field observations; read documentation by site sponsor;

2. Apply tools for evaluation, enter data information; Evaluate and triangulate data.

The data analysis process described above was also used for document analysis. Document review facilitated data triangulation such that it provided another source of data (Denzin, 2012; Jonsen \& Jehn, 2009; Yin, 2009). The triangulation helped with understanding perceptions of the four participant team role groups based on this study's research questions (Vogt, Gardner, \& Haeffele, 2012).

\section{Discussion of Results}

Research findings from the interview responses from the four ERP project role groups are discussed below according to the relevance of complexity theory during ERP implementation. 
Table 2. Relationship between Complex Categories and Critical Challenges

\begin{tabular}{|c|c|c|c|}
\hline \multirow[b]{2}{*}{ Critical Challenges } & \multicolumn{3}{|l|}{ Complex Category } \\
\hline & Human Behavior & System Behavior & Ambiguity \\
\hline Project team was disbanded very quickly & $\mathrm{X}$ & & $\mathrm{X}$ \\
\hline Interface issues & & $\mathrm{X}$ & \\
\hline Lack of proper testing & & & $\mathrm{X}$ \\
\hline Time zone limitations & & $\mathrm{X}$ & \\
\hline Implementation causes stress on people & $\mathrm{X}$ & & $\mathrm{X}$ \\
\hline Offshoring causes delays & & & $\mathrm{X}$ \\
\hline People are resistant to change & $\mathrm{X}$ & & $\mathrm{X}$ \\
\hline Short hyper-care support period & & $\mathrm{X}$ & $\mathrm{X}$ \\
\hline Lack of business buy-in from internal stakeholders & $\mathrm{X}$ & & \\
\hline Data cleanse & & $\mathrm{X}$ & \\
\hline Excessive customization is sub-optimal & & $\mathrm{X}$ & \\
\hline Leadership didn't understand the complexities & $\mathrm{X}$ & & $\mathrm{X}$ \\
\hline
\end{tabular}

The researcher analyzed the complexity theoretical implications with respect to the critical challenges in ERP implementation from the highlighted themes based on highest frequency count and complexity category (PMI, 2014), and are detailed in Table 2. ERP implementation exhibited attributes of complex systems composed of several interconnected parts having unpredictable changes, which in turn makes projects difficult to manage (Pundir et al., 2007; Simpson \& Simpson, 2009; Jacobs, M. A., 2013). Research showed a great number of challenges that emerged from the participant responses (Appendix A); however, based on highest frequency counts, the 12 top challenges are explored and highlighted (Table 2). All the top 12 challenges showed elements of project complexity in the ERP implementation at the case organization (Crawford et al., 2005; Doom et al., 2010; Finney \& Corbett, 2007; Kemp \& Low, 2008; Momoh et al., 2010; Nah et al., 2001; Poti et al., 2010; Somers \& Nelson, 2001; Themistocleus et al., 2001; Turner \& Cochrane, 1993; Yen \& Sheu, 2004). The research showed the relationship between complex categories and critical challenges (Figure 2, Table 2). The three complexity categories defined by PMI (2014) — human behavior, system behavior, and ambiguity—were mapped against each of these critical challenges (Table 2).

Human Behavior. The complexity category of human behavior showed the basis for critical challenges such as a project team's very quick disbandment, implementation causing stress on people, people's resistance to change, lack of business buy-in from internal stakeholders, and leadership's lack of understanding of the complexities (PMI, 2014; Table 2). "Quick disbandment of the project team" means that soon after the project went live, consultants were gone, and employees had to find roles within company, eventually losing all the knowledge. One comment from the business user epitomizes the challenge: "It was extremely high pressure. We lost a few players I remember on one morning at a meeting, we were missing out of ten, we were missing three persons." For the critical challenge of "implementation causes stress on people", one of the team member's words spoke of the gravity of the situation; "it was stress, was stress-related, people were stressed out."

Regarding "people resistance to change" (Finney \& Corbett, 2007; Kemp \& Low, 2008; Somers \& Nelson, 2001), one of the business user highlighted this aspect." I think the biggest challenge is people, people absolutely. People are resistant to change." There was also lack of business buy-in from internal stakeholders. One of the business users argued that "if the current system is working, why do we need to move to another ERP?" Finally, the leadership didn't understand the complexities was another critical challenge from interview responses. One team members stated, "leaders don't have a good understanding [of what] complexity involves in." These critical challenges from interview responses showed relationship to complexity category of human behavior.

System Behavior. The second complexity category of system behavior showed foundation for the critical challenges of interface issues, time zone limitations, a short hyper-care support period, data cleanse, and the sub-optimal nature of excessive customization (PMI, 2014; Table 2). The challenge on "interface issues" (Yen \& Sheu, 2004) was raised by members of business user group. One business user remarked about the significance of this critical challenge; "the challenges were interfacing; interfacing like [multiple systems], and interfacing [was] a big, big issue." Regarding short hyper-care period, one team member explained the criticality of the situation well "we were so worried about the cost of the implementation, we got rid of everybody who had any knowledge."

Data cleanse was another challenge (Finney \& Corbett, 2007; Doom et al., 2010; Somers \& Nelson, 2001) and 
one business user emphasized, "it is hard to actually articulate in some ways, but the data cleanse [is] really, really important." Excessive customization is sub-optimal (Themistocleus et al., 2001; Momoh et al., 2010) is another critical challenge that falls in the complex category of system behavior. One of the team members explained, "where you are heavily customized because then [sic] they can really take lot of run maintain costs and individual specific skill sets that you need to be able to support."

Ambiguity. The third complexity category of ambiguity, which contains emergence and uncertainty, showed support for the following critical challenges: a project team was disbanded very quickly, a lack of proper testing, implementation caused stress on people, offshoring caused delays, people were resistant to change, a short hyper-care support period, and leadership didn't understand the complexities (PMI, 2014; Table 2). These factors mostly showed a basis in both human behavior and ambiguity complexity categories. However, the critical challenge of a short hyper-care support period showed application to the complex categories of both system behavior and ambiguity.

Critical challenges related to other key areas of project complexity such as scope, culture, and learning were also figured into the full list of challenges (Appendix A). Quick disbandment of the project and a short hyper-care period indicated a lack of project scope definition. As noted by the participants, both challenges made the post-implementation period complex and challenging but extending the scope would have made the project unviable (Besner \& Hobbs, 2012). Chaos, a source of project uncertainty, originated post go-live; one of the business user participant's reference to this phenomenon as a "tsunami" is worth noting (Besner \& Hobbs, 2012). Disbanding the project team quickly meant that no personnel with project experience were present post go-live; this short-sighted move could have been mitigated by a risk management plan (Browning \& Ramasesh 2015; Maylor et al., 2013; Meyer et al., 2002; Salmeron \& Lopez, 2012; Simangunsong et al., 2012).

Two of the challenges, complications that can result from technological issues (such as leadership's lack of understanding of the complexities) and ambiguous decisions with no clear direction of outcome causing stress on people, are unpredictable conditions or unknown unknowns. These uncertainties exemplify project complexity, indicating the significance of complexity theory in ERP implementation projects (Browning \& Ramasesh, 2015; Maylor et al., 2013; Remington \& Pollack, 2007; Simangunsong et al., 2012).

\section{Conclusion}

Research on critical challenges in ERP implementation increases organizational prospects toward project success. The literature espouses many critical challenges in ERP implementation, yet these challenges are not fully recognized by organizations. The current study examined a large-scale implementation in the Canadian oil and gas industry. Despite the implementation's success, the study nevertheless produced several critical challenges from the implementation.

This research study also explored complexity theory with respect to the ERP implementation. Findings regarding critical challenges and the relationship to PMI's complex categories were of significance and identifying these challenges were considered crucial for ERP implementation.

Although other theories were not part of the study's framework, the study findings specifically considering the critical challenges of people's resistance to change, lack of business buy-in from stakeholders, and interface issues suggest that there may be implications to the theories of system and change management (Bourrie et al., 2012; Buckle Henning \& Chen, 2012; Kotter, 2012; Larsson et al., 2010; Lucas, 2005; Malek \& Yazdanifard, 2012; Poti et al., 2010; Tambovcevs \& Merkuryev, 2009).

Addressing critical challenges in an ERP implementation can provide increased visibility into the problems faced by organizations (Momoh et al., 2010; Mishra \& Mishra, 2011; Stanciu \& Tinca, 2013). Correcting critical challenges, which represent failure factors as opposed to success factors, can ensure better project performance and project success (Kimberling, 2011; Momoh et al., 2010; Stanciu \& Tinca, 2013; Shaul \& Tauber, 2013). The literature has identified critical challenges based on several studies (Ehie \& Madsen, 2005, Momoh et al., 2010). However, no comprehensive list of challenges has been compiled for the use of organizations undertaking ERP implementation. Specifically, the current study explored the critical challenges method (CCM) and compiled a comprehensive list of critical challenges (Appendix A) that can affect an ERP implementation.

Like other exploratory case studies, this study has limitations. Although the selected sample size was appropriate and within norms, the sample size was not significant enough that study population findings can be generalized (Marshal et al., 2013; Yin, 2011). The selection of 20 participants from four project role groups of senior leaders, project managers, project team members, and business users allowed acquisition of productive data on critical challenges in ERP implementation. The researcher therefore believes that if the study were to be replicated, it 
would be necessary to avoid having a general senior leader group and instead add a business leader group and an IT leader group to get both the business and IT perspectives from senior leadership, instead of one single role group of senior leaders.

\section{References}

Bansal, V., \& Negi, T. (2008). A metric for ERP complexity. Lecture Notes in Business Information Processing, 7, 369-379. https://doi.org/10.1007/978-3-540-79396-0_32

Besner, C., \& Hobbs, B. (2012). Contextualization of project management practice and best practice. Newtown Square, PA: Project Management Institute.

Bourrie, D. M., Sankar, C. S., \& McDaniel, B. (2012). The impact on ERP implementation by leadership and organisational culture: A case analysis. International Journal of Information Systems and Change Management IJISCM, 6, 112. https://doi.org/10.1504/ijiscm.2012.051149

Browning, T, R., \& Ramasesh, R, V. (2015). Reducing unwelcome surprises in project management. MIT Sloan Management Review, 56(3), 53-62.

Buckle Henning, P., \& Chen, W. C. (2012). Systems thinking: Common ground or untapped territory? Systems Research and Behavioral Science, 29(5), 470-483.

Burnes, B. (2005). Complexity theories and organizational change. International Journal of Management Reviews, 7, 73-90. https://doi.org/10.1111/j.1468-2370.2005.00107

Chapman, C. B., \& Ward, S. (1997). Project risk management: Processes, techniques and insights. Chichester, England: Wiley.

Chen, C., Law, C., \& Yang, S. (2009). Managing ERP implementation failure: A project management perspective. IEEE Transactions on Engineering Management IEEE Trans. Eng. Manage., 56, 157-170. https://doi.org/10.1109/tem.2008.2009802

Cooke-Davies, T., \& Crawford, L. (2011). Aspects of complexity: Managing projects in a complex world. Newtown Square, PA: Project Management Institute.

Cooke-Davies, T., Cicmil, S., Crawford, L., \& Richardson, K. (2007). We're not in Kansas anymore, Toto: Mapping the strange landscape of complexity theory, and its relationship to project management. Project Management Journal, 38(2), 50-61. $\quad$ Retrieved from http://www.pmi.org/Learning/Publications-Project-Management-Journal.aspx

Crawford, L., Hobbs, B., \& Turner, J. R. (2005). Project categorization systems: Aligning capability with strategy for better results. Newtown Square, PA: Project Management Institute.

Davenport, T. H. (1998). Putting the enterprise into the enterprise system. Harvard Business Review, 76(4), $121-131$.

Denzin, N. (2012). Triangulation 2.0. Journal of Mixed Methods Research, 6(2), 80-88. https://doi.org/10.1177/1558689812437186

Doom, C., Milis, K., Poelmans, S., \& Bloemen, E. (2010). Critical success factors for ERP implementations in Belgian SMEs. Journal of Enterprise Information Management, 23(3), 378-406. https://doi.org/10.1108/17410391011036120

Ehie, I. C., \& Madsen, M. (2005). Identifying critical issues in enterprise resource planning (ERP) implementation. Computers in Industry, 56(6), 545-557. https://doi.org/10.1016/j.compind.2005.02.006

Finney, S., \& Corbett, M., (2007). ERP implementation: A compilation and analysis of critical success factors. Business Process Management Journal, 13(3), 329 -347. https://doi.org/10.1108/14637150710752272

Geraldi, J., Maylor, H., \& Williams, T. (2011). Now let's make it really complex (complicated): A systematic review of the complexities of projects. International Journal of Operations and Production Management. 31(9), 966-990.

Gerring, J. (2007). Case study research: Principles and practices (1st ed.). Cambridge, UK: Cambridge University.

Ghosh, S., \& Skibniewski, M. J. (2010). Enterprise resource planning systems implementation as a complex project: A conceptual framework. Journal of Business Economics and Management, 11, 533-549. https://doi.org/10.3846/jbem.2010.26 
Gregory, R., \& Piccinini, E. (2013). The nature of complexity in IS projects and programmes, Proceedings of the 21 st European Conference on Information Systems 2013, Netherlands, 1-12.

Gubrium, J. F., \& Holstein, J. (2001). Handbook of interview research. Thousand Oaks, CA: Sage.

Hass, K. B. (2009). Managing complex projects: A new model. Vienna, VA: Management Concepts.

Hewlett, A. K. (2005). Constructive thinking from theory to practice: An exploratory study (Doctoral dissertation). Retrieved from ProQuest Dissertations and Theses database. (UMI No. NR08783)

Howe, K. (2012). Mixed methods, triangulation, and causal explanation. Journal of Mixed Methods Research, 6 , 89-96. https://doi.org/10.1177/1558689812437187

Jacobs, M. A. (2013). Complexity: Toward an empirical measure. Technovation, 33, 111-118. doi:10.1016/j.technovation.2013.01.001

Jonsen, K., \& Jehn, K. A. (2009). Using triangulation to validate themes in qualitative studies. Qualitative Research in Organizations and Management: An International Journal, 4, 123-150. doi:10.1108/17465640910978391

Kemp, M., \& Low, G. (2008). ERP innovation implementation model incorporating change management. Business Process Management Journal, 14, 228-242. https://doi.org/10.1108/14637150810864952

Kimberling, E. (2011). 2011 ERP Report: ERP implementation project costs and durations down, business benefits up. Denver, CO: Panorama Consulting. Retrieved from http://panorama-consulting.com/2011-erp-report-erp-implementation-project-costs-and-durations-down-bus iness-benefits-up/

Kotter, P.J (2012). Kotter Change Management Model. Retrieved from https://strategicsourcing.gov/sites/default/files/uploads/guiding_principles_for_leading_chang e_guide_vjune2012.pdf

Larsson, P., Dekker, S. W., \& Tingvall, C. (2010). The need for a systems theory approach to road safety. Safety Science, 48, 1167-1174. https://doi.org/10.1016/j.ssci.2009.10.006

Levy, D. (1994). Chaos theory and strategy: Theory, application, and managerial implications. Strategic Management Journal, 15, 167-178. https://doi.org/10.1002/smj.4250151011

Lucas, C. (2005). The philosophy of complexity. Retrieved from http://pssc.wdfiles.com/local--files/the-philosophy-of-complexity/A-filosofia-da-complexidade.pdf

Malek, R., \& Yazdanifard, R. (2012). Overview of change management and its implementation. Business, Economics, Financial Sciences, and Management, 149-153. https://doi.org/10.1007/978-3-642-27966-9_21

Maylor, H. R., Turner, N. W., \& Murray-Webster, R. (2013). How hard can it be?: Actively managing complexity in technology projects. Research-Technology Management, 56(4), 45-51. doi:10.5437/08956308x5602125

McLeod, J. (2010). Case study research in counseling and psychotherapy. Thousand Oaks, CA: Sage.

Meyer, A. D., Loch, C., \& Pich, M. (2002). Managing project uncertainty: From variation to chaos. IEEE Engineering Management Review, 30, 91-91. https://doi.org/10.1109/EMR.2002.1032403

Miles, M. and Huberman, M. (1994). Qualitative data analysis: An expanded sourcebook (2nd ed.). Thousand Oaks, CA: Sage.

Mishra, A., \& Mishra, D. (2011). ERP System implementation: Evidence from the oil and gas sector. Acta Polytechnica Hungarica, 8(4), 416-428.

Mittelstädt, V., Brauner, P., Blum, M., \& Ziefle, M. (2015). On the visual design of ERP systems: The role of information complexity, presentation and human factors. Procedia Manufacturing, 3, 448-455. https://doi.org/10.1016/j.promfg.2015.07.207

Momoh, A. (2015). A framework for complexity cost modelling of ERP implementation (Doctoral dissertation). Retrieved from Cranfield CERES. http://dspace.lib.cranfield.ac.uk/handle/1826/9279

Momoh, A., Roy, R., \& Shehab, E. (2010). Challenges in enterprise resource planning implementation: State-ofthe-art. Business Process Management Journal, 4, 537-565. https://doi.org/10.1108/14637151011065919

Moon, Y. B. (2007). Enterprise Resource Planning (ERP): A review of the literature. International Journal of Management and Enterprise Development, 4, 235. https://doi.org/10.1504/ijmed.2007.012679

Nah, F. F., Lau, J. L., \& Kuang, J. (2001). Critical factors for successful implementation of enterprise systems. 
Business Process Management Journal, 7, 285-296. https://doi.org/10.1108/14637150110392782

Nickson, A. (2014). A qualitative case study exploring the nature of new managerialism in UK higher education and its impact on individual academics' experience of doing research. Journal of Research Administration, 45(1), 47-80.

Nunn, R. J. (2007). Complexity theory applied to itself. Complexity and Organization, 9(1), 93-106. Retrieved from https://www.questia.com/library/journal/1P3-1325591301/complexity-theory-applied-to-itself

Pich, M. T., Loch, C. H., \& Meyer, A. D. (2002). On uncertainty, ambiguity, and complexity in project management. Management Science, 48, 1008-1023. https://doi.org/10.1287/mnsc.48.8.1008.163

Poti, S., Bhattacharyya, S., \& Kamalanabhan, T. (2010). Change processes and its impact on individuals: Perception of ERP users in India. International Journal of Information Systems and Change Management IJISCM, 4(4), 275. https://doi.org/10.1504/ijiscm.2010.036913

Project Management Institute (PMI). (2014), Navigating complexity: A practice guide. Newtown Square, PA: PMI.

Pundir, A. K., Ganapathy, L., \& Sambandam, N. (2007). Towards a complexity framework for managing projects. Emergence Complexity and Organization, 9(4), 17-25. Retrieved from http://emergentpublications.com/publications.aspx

Remington, K., \& Pollack, J. (2007). Tools for complex projects. Aldershot, UK: Gower.

Rickles, D., Hawe, P., \& Shiell, A. (2007). A simple guide to chaos and complexity. Journal of Epidemiology \& Community Health, 61, 933-937. https://doi.org/10.1136/jech.2006.054254

Salmeron, J. L., \& Lopez, C. (2012). Forecasting risk impact on ERP maintenance with augmented fuzzy cognitive maps. IEEE Transactions on Software Engineering, 38(2), 439-452. doi:10.1109/tse.2011.8

Shaul, L., \& Tauber, D. (2013). Critical success factors in enterprise resource planning systems. ACM Computing Surveys, 45(4), 1-39. https://doi.org/10.1145/2501654.2501669

Simangunsong, E., Hendry, L., \& Stevenson, M. (2012). Supply-chain uncertainty: A review and theoretical foundation for future research. International Journal of Production Research, 50(16), 4493-4523. https://doi.org/10.1080/00207543.2011.613864

Simpson, J.J., \& Simpson, M.J. (2009, May-June). System of systems complexity identification and control. Paper presented at the IEEE International Conference on System of Systems Engineering 2009, Albuquerque, NM. Abstract retrieved from http://systemsconcept.org/html/Content/Entropy_wp_rw1.pdf

Somers, T.M., \& Nelson, K. (2001). The impact of critical success factors across the stages of enterprise resource and planning implementations. Proceedings of the 34th Hawaii International Conference on System Sciences, USA, 105, 1-10. https://doi.org/10.1109/HICSS.2001.927129

Spiteri, K. J., Luca, C., Reynolds, T., \& Wilson, G. (2012). Defining a baseline complexity model for ERP Systems over SaaS. Journal of Internet Technology and Secured Transaction, 1, 86-92. https://doi.org/10.20533/jitst.2046.3723.2012.0012

Stacey, R.D. (1995). The science of complexity, Strategic Management Journal, 16(6), 477-95. Retrieved from http://smj.strategicmanagement.net/

Stanciu, V., \& Tinca, A. (2013). ERP solutions between success and failure. Accounting \& Management Information Systems, 12(4), 626-649.

Tambovcevs, A., \& Merkuryev, Y. (2009). Analysis of ERP systems implementation in the construction enterprises. Scientific Journal of Riga Technical University. Computer Sciences, 39. doi:10.2478/v10143-010-0002-1

Tarn, J.M., Yen, D.C., \& Beaumont, M. (2002). Exploring the rationales for ERP and SCM integration. Industrial Management \& Data Systems, 102(1), 26-34.

Themistocleus, M., Irani, Z., O'Keefe, R.M. and Paul, R. (2001). ERP problems and application integration issues: An empirical survey. IEEE Proceedings of the 34th Hawaii International Conference on System Sciences, USA.

Tong, Y. K., \& Arvey, R. D. (2015). Managing complexity via the competing values framework. Journal of Management Development, 34(6), 653-673. https://doi.org/10.1108/jmd-04-2014-0029 
Trochim, W. M. K., \& Donnelly, J. P. (2006). The research methods knowledge base (2nd ed.). Mason, OH: Atomic Dog.

Turner, J., \& Cochrane, R. (1993). Goals-and-methods matrix: Coping with projects with ill-defined goals and/or methods of achieving them. International Journal of Project Management, 11, 93-102. https://doi.org/10.1016/0263-7863(93)90017-H

Vogt, W., Gardner, P., \& Haeffele, L., (2012). When to Use What Research Design. New York, NY: Guilford.

Woodside, A. (2010). Case Study Research: Theory, Methods and Practice. London, UK: Emerald.

Yen, H. R., Sheu, C. (2004) Aligning ERP implementation with competitive priorities of manufacturing firms: An exploratory study. International Journal of Production Economics, 92, 207-220.

Yin, R. K. (2009). Case study research: Design and methods (4th ed.). Thousand Oaks, CA: Sage.

Yin, R. K. (2014). Case study research: Design and methods (5th ed.). Los Angeles, CA: Sage.

Appendix A. Full list of critical challenges in ERP implementation

\begin{tabular}{|c|c|c|c|c|c|}
\hline Critical Challenges in ERP & $\begin{array}{l}\text { Senior } \\
\text { Leader }\end{array}$ & $\begin{array}{l}\text { Project } \\
\text { Manager }\end{array}$ & $\begin{array}{l}\text { Project } \\
\text { Member }\end{array}$ & Team & $\begin{array}{l}\text { Business } \\
\text { User }\end{array}$ \\
\hline Bad feelings about how employees were dealt with & - & - & 1 & & - \\
\hline Change management & 1 & - & 1 & & - \\
\hline Change request controls are very strict & - & - & - & & 1 \\
\hline Changes to strategy and direction & 1 & - & - & & - \\
\hline Communication & - & 1 & 1 & & - \\
\hline Consultants did not share knowledge & - & - & 1 & & - \\
\hline Consultants lack of knowledge of other systems & - & - & 1 & & - \\
\hline Cultural differences & - & 2 & - & & 1 \\
\hline Data cleanse & - & 1 & 1 & & 1 \\
\hline Data migration across different systems & - & - & 0 & & 1 \\
\hline Data quality issues & - & - & 1 & & 1 \\
\hline Data readiness & - & - & 2 & & - \\
\hline Data validation without understanding the data & 1 & - & - & & 1 \\
\hline Engagement with users didn't provide a whole lot of detail & - & - & - & & 1 \\
\hline Ensuring external stakeholders are aware of the change & - & 1 & - & & - \\
\hline ERP implementations are not cheap & 1 & - & - & & - \\
\hline Excessive customization is sub-optimal & 1 & - & 2 & & - \\
\hline Implementation causes stress on people & - & - & 3 & & 1 \\
\hline Inconsistent KPI reporting across the organization & - & 1 & 1 & & - \\
\hline Interface issues & - & - & - & & 5 \\
\hline Issues after go-live were like a tsunami & - & - & - & & 1 \\
\hline Lack of access to people who know the information & - & - & 1 & & 1 \\
\hline Lack of access to the system & 1 & - & - & & 1 \\
\hline Lack of business ownership & - & 1 & 1 & & - \\
\hline Lack of business buy-in from internal stakeholders & - & 1 & 2 & & 1 \\
\hline Lack of experienced subject matter experts & 2 & - & - & & - \\
\hline Lack of integrated testing \& real live simulations & - & - & 2 & & - \\
\hline Lack of integration & - & - & 1 & & - \\
\hline Lack of resources & - & - & 1 & & - \\
\hline Lack of training & 1 & - & - & & 1 \\
\hline Lack of understanding of business requirements & - & - & 1 & & - \\
\hline Leader has to champion stability & - & - & - & & 1 \\
\hline Leadership changes during project & 1 & - & - & & - \\
\hline $\begin{array}{l}\text { Leadership commitment to the standard global template was } \\
\text { lacking }\end{array}$ & 1 & - & - & & - \\
\hline Leadership didn't understand the complexities & - & 1 & 2 & & - \\
\hline Learning new system was challenging to end users & - & - & - & & 2 \\
\hline Local management didn't pull the right people & - & - & - & & 1 \\
\hline
\end{tabular}




\begin{tabular}{|c|c|c|c|c|}
\hline Management did not want to hear bad news & - & - & - & 1 \\
\hline Manual interventions & 1 & - & - & 1 \\
\hline Massive re-organization before an ERP implementation & 1 & - & - & - \\
\hline Misunderstanding of scope & - & - & 1 & - \\
\hline No accountability or checks in place to get the right data & - & - & - & 1 \\
\hline No knowledge transfer from project team to business & 1 & - & - & - \\
\hline No proper testing & - & 1 & 3 & 1 \\
\hline Offshoring causes delays & - & 1 & - & 3 \\
\hline People are resistant to change & 1 & - & 1 & 2 \\
\hline People are not working towards the same goal & - & - & 1 & - \\
\hline Perception that new system should behave like old system & 1 & - & - & - \\
\hline Personality issues & - & - & 1 & - \\
\hline Pressure to be "green" on the dashboards & - & - & 1 & - \\
\hline Project team was disbanded very quickly & - & - & 4 & 2 \\
\hline Project was too long & 1 & - & 1 & - \\
\hline Respecting no-fly zone & - & - & - & 1 \\
\hline Short hyper-care support period & 1 & - & 2 & 1 \\
\hline Thin line on budget & - & 1 & - & - \\
\hline Time zone limitations & - & 2 & - & 3 \\
\hline Took long time to address the backlog & - & - & - & 1 \\
\hline Unable to deploy resources back to business & - & 1 & 2 & - \\
\hline Use of too many templates & - & - & - & 1 \\
\hline Zero experience with SAP & 1 & - & - & - \\
\hline Total & 19 & 15 & 43 & 40 \\
\hline
\end{tabular}

Note. The table shows 60 critical challenges encountered by the case organization during ERP implementation. This is based on high-frequency count across all four project role groups. A dash indicates that no member of the group reported the critical challenge.

\section{Copyrights}

Copyright for this article is retained by the author(s), with first publication rights granted to the journal.

This is an open-access article distributed under the terms and conditions of the Creative Commons Attribution license (http://creativecommons.org/licenses/by/4.0/). 